\title{
O ACESSO À JUSTIÇA COMO DIREITO FUNDAMENTAL E A CONSTRUCÇÃO DA DEMOCRACIA PELOS MEIOS ALTERNATIVOS DE SOLUÇÃO DE CONFLITOS*
}

\author{
ACCESS TO JUSTICE AS A FUNDAMENTAL RIGHT \\ AND THE CONSTRUCTION OF DEMOCRACY BY \\ MEANS OF ALTERNATIVE WAYS TO SOLVE CONFLICTS
}

\author{
Ivan Martins Tristão \\ Zulmar Fachin"
}

\begin{abstract}
Resumo: $\mathrm{O}$ artigo pretende demonstrar que o acesso à Justiça é um principio constitucional fundamental, mediante a análise entre princípios e regras e o fato de estar no bojo dos direitos fundamentais da Constituição. Também é ressaltado que dentro do "enfoque de acesso à Justiça” encontra-se a opção dos mecanismos privados de solução de litígios, bem como que tais meios cumprem o objetivo de acesso à ordem jurídica justa fora dos tribunais. Nestes termos, pretende-se demonstrar que o acesso à Justiça é forma de exercício da cidadania, sendo os mecanismos alternativos vias democráticas para efetivação daquele princípio na sua concretude.
\end{abstract}

Palavras-chave: Acesso à justiça. Direito fundamental. Democracia. Meios alternativos de solução de conflitos.

Abstract: The article intends to demonstrate that access to justice is a fundamental constitutional principle, by analysing principles and rules, as well as the fact that it is in the core of the fundamental rights in the Constitution. It is also highlighted that, inside the "focus on access to justice", lies the option of private mechanisms to solve disputes, and that such facilities comply with the objective of access to a fair legal system outside the courts. Accordingly, this paper intends to demonstrate that access to justice is a means to exercise citizenship and that the alternative mechanisms are democratic ways to accomplish this principle.

Key-words: Access to the justice. Fundamental law. Democracy. Alternative ways to solve conflicts.

Artigo derivado da dissertação de mestrado do autor Ivan Martins Tristão, com orientação do prof. Dr. Zulmar Fachin e co-orientação da prof. Dra. Tânia Lobo Muniz, doutoranda em Direito Público na Universidade de Sevilla, Espanha.

** Mestrando em Direito Negocial (UEL), com ênfase em Direito Processual Civil. Especialista em Direito Empresarial (UEL). E-mail: ivantristao@hotmail.com.

Doutor em Direito Constitucional (UFPR). Mestre em Direito (UEL). Mestre em Ciências Sociais (UEL). Professor de Direito Constitucional na Universidade Estadual de Londrina e no CESUMAR (Centro Universitário de Maringá). Vice-presidente da Comissão de Estudos Constitucionais da Ordem dos Advogados do Brasil (Seção Paraná). Presidente Executivo do IDCC - Instituto de Direito Constitucional e Cidadania. Email: zulmarfachin@uol.com.br 


\section{INTRODUÇÃO}

A partir da concepção de que o acesso à Justiça é um princípio constitucional fundamental, tendo, com esta qualidade, grande carga valorativa a fundamentar as regras, irradiando sua efetividade em todo o ordenamento jurídico, inclusive na atividade legiferante, e considerando que o referido princípio se constitui num elemento importante ao exercício da cidadania, muito se discute sobre as formas para sua ampliação e efetivação democrática.

Nesse contexto, de necessidade de acesso à Justiça como garantia à promoção da ordem jurídica justa, se insere o questionamento sobre a opção e a utilização de meios alternativos para solução de conflitos. O monopólio estatal exercido pelo Poder Judiciário não deve ser a única opção para resolver os litígios, pois a construção da democracia exige que o cidadão possa escolher outros mecanismos que sejam legítimos, para que desta forma se atenda aos anseios da sociedade.

Com o escopo de demonstrar esta proposição, será demonstrado que os princípios e as regras são espécies de normas, sendo, por oportuno, apontadas as distinções entre eles, para, em seguida, ser respondido se o acesso à Justiça é um princípio ou uma regra, até mesmo porque esta exata noção causa diferença na efetividade deste direito fundamental.

Com base nos fundamentos alcançados, notadamente de que o acesso à Justiça é um princípio constitucional fundamental, um direito fundamental que se irradia por todo o ordenamento jurídico, parte-se para o debate do "enfoque de acesso à justiça” e o exercício da cidadania, visando, ao final, demonstrar que cada um dos meios alternativos de solução de conflitos são vias democráticas para ampliação e efetivação do acesso à Justiça.

\section{PRINCÍPIOS E REGRAS}

Ao enfrentar as questões envolvendo princípios e regras não se pode olvidar da análise de José Joaquim Gomes Canotilho. Este, tendo como ponto de partida o direito constitucional português, aponta conclusões que são gerais e aplicáveis ao instituto em outros ordenamentos, tal como no ordenamento jurídico pátrio.

Em primeiro lugar, o jurista português frisa que a teoria jurídica tradicional distinguia normas e princípios, porém, ele abandona essa concepção para em sua substituição sugerir que: “(1) - as regras e princípios são duas espécies de normas; (2) - a distinção entre regras e princípios é uma distinção entre duas espécies de normas.” (CANOTILHO, 1993, p. 166). Vale ressaltar que os 
princípios são normas ainda que implícitos, vinculando e impondo deveres. (WAMBIER, 2007, p. 68).

Paulo Bonavides (2002), após analisar pormenorizadamente a evolução doutrinária referente à normatividade dos princípios, também conclui que "os princípios são normas e as normas compreendem igualmente os princípios e as regras" (p. 243). A doutrina reconhece que a teoria dos princípios se converteu no coração das Constituições (BONAVIDES, 2002, p. 253) depois de consagrada sua normatividade, a qual provém, essencialmente, da superação do embate clássico entre Direito Natural/Positivo (BONAVIDES, 2002, p. 247).

Mas, e a diferença entre princípios e regras? Esta análise é uma tarefa complexa, pois vários critérios são propostos para se tentar chegar a um resultado aceito, por exemplo: "grau de abstração, grau de determinabilidade na aplicação do caso concreto, caráter de fundamentalidade no sistema das fontes de direito, proximidade da idéia do direito, natureza normogenética" (CANOTILHO, 1993, p. 166-7).

Embora relevante cada um desses critérios, Canotilho (1993) frisa o caráter multifuncional dos princípios e apresenta uma diferenciação qualitativa, baseada nos seguintes aspectos:

(1) - os princípios são normas jurídicas impositivas de uma optimização, compatíveis com vários graus de concretização, consoante os condicionalismos fácticos e jurídicos; as regras são normas que prescrevem imperativamente uma exigência (impõem, permitem ou proíbem) que é ou não é cumprida (nos termos de Dworkin: applicable in all-ornothing fashion); a convivência dos princípios é conflitual (Zagrebelsky); a convivência de regras é antinômica. Os princípios coexistem; as regras antinômicas excluem-se; (2) - conseqüentemente, os princípios, ao constituírem exigências de optimização, permitem o balanceamento de valores e interesses (não obedecem, como as regras, à 'lógica do todo ou nada'), consoante o seu peso e a ponderação de outros princípios eventualmente conflitantes; as regras não deixam espaço pra qualquer outra solução, pois se uma regra vale (tem validade) deve cumprir-se na exacta medida das suas prescrições, nem mais nem menos; (3) - em caso de conflito entre princípios, estes podem ser objecto de ponderação, de harmonização, pois eles contêm apenas 'exigências' ou 'standards' que, em 'primeira linha' (prima facie), devem ser realizados; as regras contêm 'fixações normativas' definitivas, sendo insustentável a validade simultânea de regras contraditórias; (4) - os princípios suscitam problemas de validade e peso (importância, ponderação, valia); as regras colocam apenas questões de validade (se elas não são correctas devem ser alteradas). (p. 167-8). 
Bonavides lembra que Alexy instituiu a distinção entre regras e princípios, a qual é essencialmente semelhante à de Dworkin. Os critérios utilizados são muitos, sendo o mais freqüente o da generalidade, pelo qual "os princípios são normas dotadas de alto grau de generalidade relativa, ao passo que as regras, sendo também normas, têm, contudo, grau relativamente baixo de generalidade" (BONAVIDES, 2002, p. 249), entretanto, Bonavides também julga correta a distinção da qualidade.

Willis Santiago Guerra Filho, com semelhança à diferenciação delineada por Canotilho, assevera que regras e princípios distinguem-se quanto à sua estrutura lógica e deontológica, bem como quanto à técnica de aplicação1. Vale anotar que alguns autores ao fazerem o cotejo entre eles apontam inovações quanto ao tema, tal como Humberto Ávila ao distinguir as normas em princípios, regras e postulados.

Como visto logo mais acima, existe sim uma diferenciação qualitativa entre princípios e regras, o que não significa que eles se excluem, ao contrário, devem coexistir, pois um sistema composto somente de princípios seria falho de segurança jurídica, ante a complexidade gerada pela possibilidade de existência de conflitos entre eles, e, de outro norte, um sistema exclusivamente de regras acarretaria num legalismo indesejado, por não possibilitar a introdução de "balanceamento de valores e interesses de uma sociedade pluralista e aberta" (CANOTILHO, 1993, p. 169).

Os princípios são necessários ao sistema jurídico principalmente porque exprimem valores, o que implica dizer que viabilizam a introdução de

\footnotetext{
1 "Regras e princípios distinguem-se: a) quanto à sua estrutura lógica e deontológica, pela circunstância de as primeiras vincularem-se a fatos hipotéticos (Tatbestande) específicos, um determinado funtor ou operador normativo ('proibido', 'obrigatório', 'permitido'), enquanto aqueles outros - os princípios - não se reportam a qualquer fato particular, e transmitem uma prescrição programática genérica, para ser realizada na medida do jurídico e faticamente possível. Dessa diferença estrutural básica decorrem inúmeras outras, como: b) quanto à técnica de aplicação, já que princípios normalmente colidem entre si, diante de casos concretos, o que leva ao chamado 'sopesamento' (Abwägung), para aplicar o mais adequado, ao passo que regras, uma vez aceita a subsunção a elas de certos fatos, inevitavelmente decorrem as conseqüências jurídicas nelas previstas, a não ser que elas não sejam válidas por conflitarem com outras de um grau superior, quando então, ao contrário do que se dá com os princípios, que apesar de contraditórios não deixam de integrar a ordem jurídica, a regra de grau inferior é derrogada.” (GUERRA FILHO, 2001, p. 127-8).

2 "Os postulados normativos são normas imediatamente metódicas, que estruturam a interpretação e aplicação de princípios e regras mediante a exigência, mais ou menos específica, de relação entre elementos com base em critérios." (ÁVILA, 2007, p. 181).
} 
ponderações e interpretações atuais sobre os conflitos de uma dada sociedade e, por isso, "são o fundamento de regras jurídicas e têm uma idoneidade irradiante que lhes permite 'ligar' ou cimentar objectivamente todo o sistema constitucional” (CANOTILHO, 1993, p. 169).

Por isso tudo, Canotilho defende que a existência de regras e princípios viabiliza a compreensão da constituição como um sistema aberto de regras e princípios, de diferente grau de concretização e desenvolvimento. Análise bastante utilizada no Brasil como suporte para explicar o pós-positivismo (GUERRA FILHO, 2001, p. 147), em razão da visão principialista do sistema constitucional ${ }^{3}$.

Portanto, as regras e os princípios são espécies de normas, se distinguindo, especialmente, qualitativamente, em razão dos princípios possuírem grande carga valorativa, além de serem fundamentos das regras e irradiarem sua força normativa por todo sistema constitucional e, por conseguinte, toda legislação infraconstitucional.

\section{O ACESSO À JUSTIÇA É UM PRINCÍPIO OU UMA REGRA?}

Com base na tipologia de princípios e regras no âmbito constitucional formulada por Canotilho ${ }^{4}$, tem-se que o acesso à Justiça é um princípio jurídico fundamentaF. Estes, "pertencem à ordem jurídica positiva e constituem um importante fundamento para a interpretação, integração, conhecimento e aplicação do direito positivo" (CANOTILHO, 1993, p. 171) e, ainda,

\footnotetext{
${ }^{3}$ Neste sentido, Bonavides concluiu que "em verdade, os princípios são o oxigênio das Constituições na época do pós-positivismo. É graças aos princípios que os sistemas constitucionais granjeiam a unidade de sentido e auferem a valoração de sua ordem normativa." (BONAVIDES, 2002, p. 259).

4 "A estrutura da tipologia apresentada é a seguinte: Princípios: 1. Princípios jurídicos fundamentais; 2. Princípios políticos constitucionalmente conformadores; 3. Princípios constitucionais impositivos; 4. Princípios-garantia. Regras: 1. Regras jurídico-organizatórias: a) regras de competência, b) regras de criação de órgãos (normas orgânicas), c) regras de procedimento; 2. regras jurídico-materiais: a) regras de direitos fundamentais, b) regras de garantias institucionais, c) regras determinadoras de fins e tarefas do Estado, d) regras constitucionais impositivas." (CANOTILHO, 1993, p. 171-80, passim).

5 “[...] o princípio do acesso ao direito e aos tribunais (cfr. art. 20.) é outro princípio geral que postula não só o reconhecimento da possibilidade de uma defesa sem lacunas, mas também o exercício efectivo deste direito (ex.: direito ao patrocínio judiciário, direito à informação jurídica).” (CANOTILHO, 1993, p. 171-2).
} 
[...] fornecem sempre directivas materiais de interpretação das normas constitucionais. Mais do que isso: vinculam o legislador no momento legiferante, de modo a poder dizer-se ser a liberdade de conformação legislativa positiva e negativamente vinculada pelos princípios jurídicos gerais. (CANOTILHO, 1993, p. 171-2).

Com efeito, e considerando as distinções já apresentadas, não se pode negar que o acesso à justiça é um verdadeiro princípio constitucional no ordenamento brasileiro. Conforme Sérgio Alves Gomes, "princípios constitucionais são normas jurídicas fundamentais que servem de sustentação às regras constitucionais, bem como aos princípios e regras infraconstitucionais, compondo com este um todo denominado ordenamento jurídico.” (GOMES, 2001, p. 68).

Ele está inserido no artigo 5º, inciso XXXV, da Constituição Federal de 1988, expressado nos seguintes termos: "a lei não excluirá do Poder Judiciário lesão ou ameaça de direito.” O princípio do acesso à Justiça, que tantos sinônimos possui ${ }^{6}$, teve origem expressa na constituição de 1946, embora já estivesse presente de forma implícita na Constituição de $1981^{7}$.

Entre os elementos fundamentais considerados como o mínimo irredutível de uma autêntica Constituição, Karl Loewenstein aponta a existência de direitos individuais e liberdades fundamentais, além da sua proteção frente à intervenção de um ou todos os detentores do poder. (LOEWENSTEIN, 1970, p. 153). ${ }^{8}$ E, de fato, nesta esteira a Constituição, no artigo $5^{\circ}$, caput e incisos, enumera os direitos e garantias fundamentais, individuais e coletivos, onde está incluso o princípio do acesso à Justiça, até mesmo porque são nos princípios que se situam as normas de direito fundamentais (GUERRA FILHO, 1999, p. 44).

A Constituição é o "fundamento de validade último de todas as demais normas do ordenamento jurídico" (BASTOS, 1999, p. 52), inclusive na atividade

\footnotetext{
${ }^{6}$ Por exemplo, princípio de acesso da inafastabilidade da jurisdição, ou, conforme Celso Ribeiro Basto, princípio da acessibilidade ampla do Poder Judiciário (BASTOS, 1996, p. 197), ou, tantos vários outros nomes, conforme enumeram Luiz Alberto David Araújo e Vidal Serrano Nunes Júnior: princípio do livre acesso ao Poder Judiciário, princípio do controle jurisdicional e princípio da ubiqüidade da justiça. (ARAÚJO; NUNES JÚNIOR, 2001, p. 127).

7 "O princípio da acessiblidade ampla ao Poder Judiciário nasceu com a Constituição de 1946, que tinha uma redação quase idêntica à atual: 'A lei não poderá excluir da apreciação do Poder Judiciário qualquer lesão de direito individual'. Pontes de Miranda, contudo, observa com muito acerto que este princípio já poderia ser tido como presente na Constituição de 1891, porque na verdade estava implícito na sistemática constitucional então adotada.” (MARTINS; BASTOS, 1988-1989, p. 170).

${ }^{8}$ Ao texto, que é antigo, poderia se incluir atualmente os direitos sociais.
} 
interpretativa (p. 80), por isso, qualquer norma infraconstitucional que esteja em conflito com o acesso à Justiça pode (e deve) ser afastada. De outro norte, interessa destacar que as normas constitucionais possuem um caráter aberto, surgindo a possibilidade de sua interpretação ser atualizada ${ }^{9}$, de acordo com os anseios da sociedade.

Konrad Hesse (1983) propunha que a interpretação constitucional é concretização vinculada à norma, ou seja, incorporação da realidade com observância do texto constitucional. O conteúdo da norma interpretada só fica completo com sua interpretação. Diferente das regras, os princípios perdem na objetividade, mas ganham na abrangência interpretativa. (BASTOS, 1999).

Portanto, o acesso à justiça é verdadeiro princípio constitucional fundamental, um direito fundamental que deve nortear a interpretação constitucional e servir como diretriz para a atividade interpretativa, influenciando, assim, todo o ordenamento jurídico, desde o momento legiferante, passando pela aplicação concreta da lei até a necessidade de se franquear opções para sua efetivação, justamente o que possibilita uma construção da democracia de forma justa e igualitária.

\section{O “ENFOQUE DE ACESSO À JUSTIÇA” E SUA EFETIVAÇÃO POR MEIO DA VIA DEMOCRÁTICA DOS MEIOS ALTERNATIVOS DE SOLUÇÃO DE CONFLITOS}

O movimento do acesso à Justiça tem como marco a obra de Mauro Cappelletti e Bryant Gart, onde identificam alguns obstáculos que devem ser transpostos, a exemplo das custas judiciais, das pequenas causas e do tempo (CAPPELLETTI; GARTH, 1988), e apresentam algumas soluções práticas, baseadas, principalmente, em três posições: assistência judiciária, representação jurídica para os interesses difusos e enfoque de acesso à justiça.

Esta terceira onda do referido movimento incluiu os outros dois posicionamentos e vai além, na tentativa de atacar as barreiras ao acesso de modo mais articulado e compreensivo ${ }^{10}$. Busca-se explorar uma ampla variedade

9 "A norma constitucional, muito freqüentemente, apresenta-se como uma petição de princípios ou mesmo como uma norma programática sem conteúdo preciso ou delimitado. Como conseqüência direta desse fenômeno, surge a possibilidade da chamada 'atualização’ das normas constitucionais.” (BASTOS, 1999, p. 54).

10 "O recente despertar de interesse em torno do acesso efetivo à Justiça levou a três posições básicas, pelo menos nos países do mundo Ocidental. Tendo início em 1965, estes posicionamentos emergiram mais ou menos em seqüência cronológica. Podemos afirmar que a primeira solução para o acesso - a primeira 'onda' desse movimento 
de reformas, inclusive a utilização de mecanismos privados ou informais de solução de litígios:

Inicialmente, como já assinalamos, esse enfoque encoraja a exploração de uma ampla variedade de reformas, incluindo alterações nas formas de procedimento, mudanças na estrutura dos tribunais ou a criação de novos tribunais, o uso de pessoas leigas ou paraprofissionais, tanto como juízes quanto como defensores, modificações no direito substantivo destinadas a evitar litígios ou facilitar sua solução e a utilização de mecanismos privados ou informais de solução dos litígios. (CAPPELLETTI; GARTH, 1988, p. 70-1).

Com efeito, entre as tendências no uso do enfoque do acesso à Justiça, Mauro Cappelletti e Bryant Gart imaginam métodos alternativos para decidir causas judiciais mediante a criação de alternativas, utilizando, para tanto, procedimentos mais simples e/ou julgadores mais informais, sendo exemplo o juízo arbitral, a conciliação e os incentivos econômicos para a solução dos litígios fora dos tribunais. ${ }^{11}$

Há muito tempo a doutrina defende a idéia de que o acesso à Justiça não deveria se limitar exclusivamente a atuação judicial, mas extrajudicial também (TUCCI; CRUZ E TUCCI, 1989). Realmente, o acesso à Justiça deve conter diversos meios de pacificação de conflitos, assim como a ordem jurídica deve oferecer instrumentos hábeis à consecução, rápida, segura e justa de uma pretensão. ${ }^{12}$

novo - foi a assistência judiciária; a segunda dizia respeito às reformas tendentes a proporcionar representação jurídica para os interesses 'difusos', especialmente nas áreas da proteção ambiental e do consumidor; e o terceiro - e mais recente - é o que nos propomos a chamar simplesmente 'enfoque de acesso à justiça' porque inclui os posicionamentos anteriores, mas vai muito além deles, representando, dessa forma, uma tentativa de atacar as barreiras ao acesso de modo mais articulado e compreensivo." (CAPPELLETTI; GARTH, 1988, p. 31).

11 "Os reformadores estão utilizando, cada vez mais, o juízo arbitral, a conciliação e os incentivos econômicos para a solução dos litígios fora dos tribunais. Essas técnicas, é preciso que se diga, podem ser obrigatórias para algumas ou todas as demandas, ou podem tornar-se disponíveis como opção para as partes.” (CAPPELLETTI; GARTH, 1988, p. 81).

12 "Não basta para o jurisdicionado envolvido numa lide judicial que o Estado diga o direito; torna-se imprescindível que esse direito seja conferido materialmente a quem tem razão, isto é, que a pretensão se efetive através do instrumento colocado à disposição do vencedor e que esteja em sintonia com os princípios constitucionais processuais. Para tanto, faz-se mister que o acesso à justiça (entenda-se aqui a expressão como meios diversos de pacificação de conflitos) seja amplo e irrestrito, assim como a ordem jurídica oferecida deve necessariamente ser justa (capaz de oferecer mecanismos hábeis à consecução rápida, segura e justa de uma pretensão resistida ou insatisfeita." (FIGUEIRA JÜNIOR, 1999, p. 134). 
O direito de acesso à Justiça ou acesso à ordem jurídica justa é denominação genérica do direito fundamental à efetividade do processo. O texto constitucional consagra o acesso à Justiça de forma ampla, compreendendo a obtenção de tutela jurisdicional qualificada e efetiva (LOPES, 2005, v. 1). José Roberto dos Santos Bedaque, expõe que o Judiciário deve garantir um efetivo acesso à ordem jurídica justa, colocando à disposição de todas as pessoas mecanismos destinados a satisfação do direito:

Muito mais do que prever mera formulação de pedido ao Poder Judiciário, a Constituição da República garante a todos o efetivo acesso à ordem jurídica justa, ou seja, coloca à disposição de todas as pessoas mecanismo destinado a proporcionar a satisfação do direito. Não basta, pois, assegurar abstratamente o direito de ação a todos aqueles que pretendam valer-se do processo. É necessário garantir o acesso efetivo à tutela jurisdicional, por parte de quem dela necessita. Acesso à justiça ou, mais propriamente, acesso à ordem jurídica justa significa proporcionar a todos, sem qualquer restrição, o direito de pleitear a tutela jurisdicional do Estado e de ter à disposição o meio constitucionalmente previsto para alcançar esse resultado. Ninguém pode ser privado do devido processo legal, ou melhor, do devido processo constitucional. (BEDAQUE, 1999, p. 151, 153, 158; grifos nosso).

Neste sentido, Kazuo Watanabe enfatiza que "a problemática do acesso à Justiça não pode ser estudada nos acanhados limites dos órgãos judiciais já existentes. Não se trata apenas de possibilitar o acesso à Justiça enquanto instituição estatal, e sim de viabilizar o acesso à ordem jurídica justa.” (WATANABE, 1988, p. 128).

Estudos recentes têm incluído o efetivo acesso à Justiça como um elemento essencial ao exercício integral da cidadania, tendo como fundamento o fato de não haver cidadania sem efetivo acesso à Justiça, conforme obra de Alexandre César:

A garantia de efetivo acesso à Justiça também constitui um Direito Humano $\mathrm{e}$, mais do que isto, um elemento essencial ao exercício integral da cidadania, já que, indo além do simples acesso à tutela jurisdicional, não se limita ao

${ }^{13}[. .$.$] o processo deve ser manipulado de modo a propiciar às partes o acesso à justiça, \mathrm{O}$ qual se resolve, na expressão muito feliz da doutrina brasileira recente, em 'acesso à ordem jurídica justa'. Acesso à justiça não se identifica, pois, com a mera admissão ao processo, ou possibilidade de ingresso em juízo. (CINTRA; GRINOVER; DINAMARCO, 2000, p. 33).

14 "[...] idéias como a de instrumentalidade e efetividade passaram a dar a tônica do processo contemporâneo.” (THEODORO JÚNIOR, 2001, v. 1, p. 8). 
mero acesso ao Poder judiciário. Por conta disto é que José Alfredo de Oliveira Baracho afirma que ele 'é primordial à efetividade dos direitos humanos, tanto na ordem jurídica interna como na internacional. O cidadão tem necessidade de mecanismos próprios e adequados para que possa efetivar seus direitos'. (CESAR, 2002, p. 52).

Todas as perspectivas estão sendo abordadas para um único fim: ampliar e dar efetividade ao acesso à Justiça, pois a busca de solução de litígios por outros meios é alternativa perfeitamente válida e democrática, sem que isso signifique desprestígio direto ao Poder Judiciário.$^{15}$

Portanto, a utilização de meios alternativos para solução de conflitos, ou meios alternativos de pacificação social(CINTRA; GRINOVER; DINAMARCO, 2000), é um problema de grande relevância doutrinária e prática, além de ser uma tendência mundial ${ }^{16}$, pois é uma via legítima, por ser democrática, para ampliar e dar maior efetividade ao acesso à Justiça, na sua concepção de acesso à ordem jurídica justa e, por conseguinte, se constitui num elemento essencial na construção da democracia.

\section{MEIOS ALTERNATIVOS DE CONFLITOS}

Os princípios (e neste caso as regras também) necessitam de mecanismos para que sejam operacionalizados, sejam por meio de procedimentos legislativos e administrativos, iniciativas dos cidadãos ou processos judiciais. O horizonte é amplo e por isso a criação de alternativas aos instrumentos estatais de solução de conflitos constitui hoje a maior área de inovação na política judiciária. (CESAR, 2002).

No mundo, notadamente no âmbito do direito internacional, e no ordenamento jurídico pátrio, o meio alternativo de solução de conflito que possui maior destaque, como via legítima de ampliação do acesso à Justiça ${ }^{17}$, é a arbitragem, a qual possui regulamentação na Lei no 9.307, de 23.9.96 e pode

15 "A busca da solução de litígios por meio de arbitragem é alternativa perfeitamente válida e democrática, devendo ser acolhida como parte da normalidade de um Estado de Direito, não implicando a redução do prestígio e da importância do Poder Judiciária, que, em muitos casos, será insubstituível.” (DALLARI, 2001, p. 109).

16 "A idéia de resolver conflitos de direitos e de interesses mediante arbitragem, como alternativa para a solução por via judicial, vem sendo muito enfatizada ultimamente em diferentes partes do mundo. São vários os motivos dessa ênfase, parecendo que o principal deles é a demora crescente para obtenção de uma decisão judicial definitiva. Isso vem sendo assinalado em muitos países, mesmo naqueles cujos respectivos sistemas jurídicos são bem diferentes, como é o caso da Itália e dos Estados Unidos." (DALLARI, 2001, p. 99). 
Acesso à justiça como direito fundamental e a construção da democracia...

ser definida como

uma técnica para a solução de controvérsias através da intervenção de uma ou mais pessoas que recebem seus poderes de uma convenção privada, decidindo com base nesta convenção, sem intervenção do Estado, sendo a decisão destinada a assumir eficácia de sentença judicial. As pessoas que queiram utilizar este meio de solução de controvérsia devem ser capazes (capacidade civil) e o litígio deverá versar sobre direitos patrimoniais disponíveis. (CACHAPUZ, 2000, p. 22).

Em que pesem algumas controvérsias, principalmente sobre sua natureza jurídica ${ }^{18,19}$, a qual se entende ser hibrida ${ }^{20}$, é possível destacar que na arbitragem a questão litigiosa, dentro de seus limites $^{21}$, será decidida por terceiros devidamente escolhidos por convenção privada, sem intervenção do Estado. A decisão terá os mesmos efeitos dos julgados proferidos pelo Poder Judiciário e não precisará de homologação judicial, valendo, inclusive, como título executivo, se for condenatória. ${ }^{22}$

17 "Em síntese, prestigia-se o reconhecimento do acesso à justiça (ou acesso aos tribunais) através da ampliação de três vertentes autônomas, que terminam por desaguar no leito do mesmo rio: da legitimidade ativa ad causam; dos instrumentos de tutela diferenciada e dos métodos alternativos de solução de conflitos e, em particular, das técnicas de arbitragem.” (FIGUEIRA JÚNIOR, 1999, p. 141).

18 "Dentre as teorias que procuram explicá-la, vamos encontrar a dos publicistas que, salientando a atuação do árbitro de dizer o direito, lhe atribuem natureza jurisdicional, a dos privatistas que, dando destaque à figura da convenção arbitral, ressaltam sua natureza como puramente contratual, e a daqueles que, dando igual ênfase às duas fases da arbitragem e conciliando os dois aspectos, vão caracterizála como de natureza híbrida, considerando os aspectos contratual e jurisdicional." (MUNIZ, 1999, p. 30).

${ }^{19}$ Entre outros, defendem a natureza jurisdicional: Carmona (1993, p. 36) e Nery Júnior (2004, p. 115-116).

20 “Em posição conciliadora surge a noção da natureza jurídica híbrida, apresentando aspecto contratual em sua primeira fase, em razão da convenção arbitral que lhe dá nascimento, e jurisdicional na segunda, vista como forma privada de dizer o direito, fazer a justiça, solucionar o litígio, através de uma atividade ordenada para tal fim, que se dá com a instalação e desenvolvimento do juízo arbitral e, principalmente ante sua natureza pública, por decorrer de lei a possibilidade de sua utilização, a criação do órgão arbitral (com função e competência próprios) e os efeitos da sentença arbitral que o encerra.” (MUNIZ, 1999, p. 35-36).

21 "Art. 1‥ As pessoas capazes de contratar poderão valer-se da arbitragem para dirimir conflitos relativos a direitos patrimoniais disponíveis."

22 “a) convenção de arbitragem (compromisso entre as partes ou cláusula compromissória inserida em contrato: lei cit., art. $3^{\circ}$ ); b) limitação aos litígios relativos a direitos patrimoniais disponíveis (art. $\left.1^{\circ}\right)$; c) restrições à eficácia da cláusula compromissória inserida em contratos de adesão (art. $4^{\circ}, \S 2^{\circ}$ ); d) capacidade das partes (art. 1을 ; e) possibilidade de escolherem as partes as regras de direito material a serem aplicadas 
Visto isso, interessa destacar que Cappelletti e Garth já defendiam a arbitragem como meio de acesso à Justiça, ao ressaltarem que "a sobrecarga dos tribunais e as despesas excessivamente altas com os litígios podem tornar particularmente benéficas para as partes as soluções rápidas e mediadas, tais como o juízo arbitral” (CAPPELLETTI; GARTH, 1988, p. 83).

Paulo de Tarso Santos proclama que "a Lei 9.307 tem o sentido de uma mudança cultural” (SANTOS, 2001, p. 75). Chega a propor uma cultura da arbitragem, sob o fundamento de que "[...] para ultrapassar, na prática, a opção única pela jurisdição estatal, exercida pelo poder Judiciário, é preciso formar o hábito de considerar a alternativa arbitral [...]” (SANTOS, 2001, p. 77). Entre os exemplos práticos, chega a propor a inclusão da arbitragem nos currículos universitários. (SANTOS, 2001).

A arbitragem é muito defendida no comércio internacional, principalmente em razão de demandar pouco tempo e contar com profissionais especializados na área de conflito de interesses. ${ }^{23} \mathrm{Em}$ alguns casos chega a ter preferência de $100 \%$ dos casos. $^{24}$

Ademais, "a arbitragem internacional tem ganhado, atualmente, muito espaço no campo das relações privadas, porém, na esfera dos espaços de integração, mostra-se como fundamental instrumento da resolução das

na arbitragem, sendo ainda admitido convencionar que esta 'se realiza com base nos princípios gerais de direito, nos usos e costumes e nas regras internacionais de comércio' (art. 2을 $\S \S 2^{\circ}$ e $3^{\circ}$ ); f) desnecessidade de homologação judicial da sentença arbitral (art. 31); g) atribuição a esta dos mesmos efeitos, entre partes, dos julgados proferidos pelo Poder Judiciário (valendo inclusive como título executivo, se for condenatória: art. 31); h) possibilidade de controle jurisdicional ulterior, a ser provocado pela parte interessada (art. 33, caput e \$§); i) possibilidade de reconhecimento e execução de sentença arbitrais produzidas no exterior (arts. 34 ss.). Mas os árbitros, não sendo investidos do poder jurisdicional estatal, não podem realizar a execução de suas próprias sentença nem impor medida coercitivas (art. 22, $\S 4^{\circ}$ ). (CINTRA; GRINOVER; DINAMARCO, 2000, p. 30-1).

23 "Porém, por ser uma forma de solução de controvérsia extrajudicial, só agora começa-se a perceber que a Arbitragem é o futuro das relações humanas, por não demandarem tanto tempo nas resoluções, por serem decisões de pessoas profissionais nas área de conflitos de interesses, o que daí advirá soluções com técnica apurada e conseqüentemente satisfação das partes em litígio." (BEZERRA JÚNIOR, 2001, p. 8).

24 "Atualmente, estima-se que cerca de 90\% dos contratos internacionais de comércio contêm uma cláusula arbitral. Em contratos internacionais referentes à construção de complexos industriais e projetos de construção similares, o índice de cláusulas arbitrais, inseridas nestes contratos, atinge a cerca de 100\%. Neste terreno, a decisão das lides decorrentes de tais relações jurídicas é atribuída, basicamente, a tribunais arbitrais e não aos tribunais estatais. (RECHSTEINER, 2001, p. 15). 
controvérsias ente os Estados-membros dos mais variados blocos” (NOHMI, 2005, 76). A globalização e a participação do Brasil no Mercosul também são fatores importes que contribuem para a preferência da arbitragem como meio de solução de conflitos. ${ }^{25}$

Não é só no campo internacional que a arbitragem vem tendo destaque, pois cada vez mais os juristas estudam meios para utilizá-las em outras áreas. Ives Gandra da Silva Martins defende propostas para utilizar a arbitragem no âmbito tributário, ao considerar que "a arbitragem é, pois, caminho de que não se deve ter receio, mesmo em se admitindo o instituto para um campo tão polêmico como o do direito tributário” (MARTINS, 2001, p. 153).

Márcio Yoshida (1997), por sua vez, faz propostas em relação a alguns direitos do trabalho, considerando "é certo que, conquanto a Lei $n^{\circ}$ 9.307 abranja somente a arbitragem de questões que envolvam direitos patrimoniais disponíveis, poderá ser utilizada, em larga escala, no universo das relações do trabalho" (p. 80). Enfim, muitas são as possibilidades.

Além da arbitragem, Cappelletti e Gart (1988) também defendem que na terceira onda do acesso à Justiça “já foi sugerido que a mediação ou outros mecanismos de interferência apaziguadora são os métodos mais apropriados para preservar os relacionamentos” (p. 72). A mediação tem como pilares a boafé e a confiança ${ }^{26}$, que "pode ser aplicada a diversos tipos de conflitos como os civis, comerciais, de família, interorganizacionais, sejam públicas ou privadas as organizações, relativos à saúde e ao meio ambiente, trabalhistas, urbanísticos, escolares, internacionais, etc.” (COLAIÁCOVO; COLAIÁCOVO, 1999, p. 71).

Inclusive, ela pode ser exercida por advogados e juízes, na função de mediadores judiciais, com aplicação de senso de justiça, crença nos benefícios e consciência de sua necessidade ${ }^{27}$, além das características sugeridas pela American Arbitration Association. ${ }^{28}$

25 "Com o advento da globalização, e o Brasil envolvido com o MERCOSUL, a tendência lógica é a opção pela arbitragem nos contratos que envolvam direitos patrimoniais disponíveis." (SANT’ANA, 1997, p. 23).

26 "a) E a técnica mediante a qual as partes envolvidas no conflito buscam chegar a um acordo contando com a ajuda de um mediador, terceiro imparcial, que não tem poder de decisão. b) É um processo de negociação assistido por um terceiro, o mediador, escolhido de comum acordo pelas partes, a quem são atribuídas funções específicas, com o fim de possibilitar a solução de um conflito. A mediação caracteriza-se por se tratar de um processo voluntário, confidencial, flexível, e participativo." (COLAIÁCOVO; COLAIÁCOVO, 1999, p. 66).

27 "(a) sendo de justiça; (b) crença nos benefícios da conciliação aos litigantes; (c) consciência da gravidade da situação quanto à incapacidade das partes em solucionar, sozinhas, a questão.” (SOUZA NETO, 2000, p. 52-53). 
Além desses meios, também há a possibilidade de melhor utilização da conciliação. Embora alerte para certificar se os resultados representam verdadeiros êxitos, Cappelletti e Garth não deixam de destacar que "a conciliação é extremamente útil para muitos tipos de demandas e partes, especialmente quando consideramos a importância de restaurar relacionamentos prolongados, em vez de simplesmente julgar as partes vencedoras ou vencidas" (CAPPELLETTI; GARTH, 1988, p. 87).

Por fim, pode-se citar a negociação $0^{29}$, que ainda tem o condão de fortalecer os vínculos interpessoai ${ }^{30}$ entre as partes que a utilizam. Portanto, os meios alternativos de solução de conflitos se concretizam em vias democráticas para ampliar o acesso à Justiça, na concepção de ordem jurídica justa e caminho para o melhor exercício da cidadania.

\section{CONSIDERAÇÕES FINAIS}

Conforme se sustentou, o acesso à Justiça, principalmente na sua concepção de acesso à ordem jurídica justa, franqueia aos indivíduos mais cidadania. A efetivação deste princípio pode ser ampliada através dos meios alternativos de solução de conflitos, pois se constituem numa via democrática para resolver os

28 "Logo, impõe-se que os juízes e advogados, doravante tratados como mediadores judiciais, ajam, tanto quanto possível, com as características a seguir descritas, sugeridas pela American Arbitration Association: (a) facilitando a comunicação; (b) permitindo que as pessoas em disputa examinem o problema baseadas em várias perspectivas, ajuda nas definições das questões e dos interesses básicos e procura de opções mutuamente satisfatórias; (c) auxiliando a elaboração de um acordo razoável e viável; (d) desenvolvendo as negociações via formulação das adequadas sugestões de encaminhamento." (SOUZA NETO, 2000, p. 52).

29 “[...] um processo pelo qual duas ou mais partes interagem em uma situação de conflito/transação/desenvolvimento de idéias, segundo regras estabelecidas com ou sem a participação de intervenientes, objetivando o acordo entre as partes ou a busca de um consenso que satisfaça interesses de comunicação, persuasão e poder, através dos quais são canalizadas, no âmbito de estratégias e táticas negociadoras, informações sob a forma de propostas e argumentos." (COLAIÁCOVO; COLAIÁCOVO, 1999, p. 33).

30 “A negociação, valorizada como instrumento idôneo para o tratamento do conflito, também tenderá a mudanças de paradigmas, com a diminuição do enfoque ganharperder, baseado na confrontação e no domínio sobre o outro, e o crescimento do enfoque baseado, preferencialmente, na negociação cooperativa baseada na satisfação de interesses e não na avaliação das condições de confrontação. Uma vez que a interação passa a ter caráter estratégico, o relacionamento entre as partes, a longo prazo, deve primar pela qualidade. O processo de negociação fortalecerá os vínculos interpessoais." (COLAIÁCOVO; COLAIÁCOVO, 1999, p. 19). 
interesses das pessoas e servir como legítimo instrumento de pacificação social, escopo da jurisdição.

Nesse sentido, cada mecanismo de solução alternativa de conflito representa uma forma de ampliar o acesso à Justiça. Este, é um direito fundamental alçado à qualidade de princípio constitucional fundamental que deve ser visto como um fim a ser perseguido por todos que estão acobertados pelo ordenamento jurídico e, por isso, deve ser amplamente franqueado aos cidadãos.

Somente com a ampliação do acesso à Justiça, que é um direito fundamental e que pode ser efetivado por meio dos meios de solução de conflitos, podese afirmar com segurança que a democracia está sendo construída de forma efetiva, concreta, de acordo com os anseios da sociedade.

\section{REFÊRENCIAS}

ARAÚJO, Luiz Alberto David; NUNES JÚNIOR, Vidal Serrano. Curso de Direito Constitucional. 4. ed. São Paulo: Saraiva, 2001.

ÁVILA, Humberto. Teoria dos princípios: da definição à aplicação dos princípios jurídicos. 7. ed. São Paulo: Malheiros, 2007.

BASTOS, Celso Ribeiro. Curso de Direito Constitucional. 17. ed. São Paulo: Saraiva, 1996.

. Hermenêutica e interpretação constitucional. 2. ed. São Paulo: Celso Bastos Editor, 1999.

BARROSO, Luís Roberto. Interpretação e aplicação da Constituição. São Paulo: Saraiva, 1996.

BEDAQUE, José Roberto. Garantia da Amplitude de Produção Probatória. In: CRUZ E TUCCI, José Rogério (Coord.). Garantias constitucionais do processo civil. São Paulo: RT, 1999.

BEZERRA JÚNIOR, Wilson Fernandes. Arbitragem comercial no direito de integração. São Paulo: Aduaneiras, 2001.

BONAVIDES, Paulo. Curso de Direito Constitucional. 12. ed. São Paulo: Malheiros, 2002.

CANOTILHO, José Joaquim Gomes. Direito Constitucional. 6. ed. Coimbra: Almedina, 1993.

CACHAPUZ, Rozane da Rosa. Arbitragem: alguns aspectos do processo e do procedimento na lei $\mathrm{n}^{\mathbf{a}}$ 9.307/96. São Paulo: Editora de Direito, 2000. 
CARMONA, Carlos Alberto. A arbitragem no Processo Civil brasileiro. São Paulo: Malheiros, 1993.

CAPPELLETTI, Mauro; GARTH, Bryant. Acesso à justiça. Trad. Ellen Gracie Northfleet. Porto Alegre: Fabris, 1988.

CESAR, Alexandre. Acesso à justiça e cidadania. Cuiabá: EdUFMT, 2002.

CINTRA, Carlos de Araújo; GRINOVER, Ada Pellegrini; DINAMARCO, Cândido Rangel. Teoria geral do processo. 16. ed. rev. e atual. São Paulo: Malheiros, 2000.

COLAIÁCOVO, Juan Luis; COLAIÁCOVO, Cynthia Alexandra. Negociação, mediação e arbitragem: teoria e prática. Trad. Adilson Rodrigues Pires. Rio de Janeiro: Forense, 1999.

DALLARI, Dalmo de Abreu. A tradição da arbitragem e sua valorização contemporânea. In: PUCCI, Adriana Noemi (Coord.). Aspectos atuais da arbitragem: coletânea de artigos dos árbitros do centro de conciliação e arbitragem da câmara de comércio argentino-brasileira de São Paulo. Rio de Janeiro: Forense, 2001.

FIGUEIRA JÚNIOR, Joel Dias. Arbitragem, jurisdição e execução: análise crítica da lei 9.307, de 23.09.1996. 2. ed. São Paulo: RT, 1999.

GOMES, Sérgio Alves. Hermenêutica jurídica e Constituição no Estado de Direito Democrático. 2. ed. Rio de Janeiro: Forense, 2001.

GUERRA FILHO, Willis Santiago. Processo constitucional e direitos fundamentais. São Paulo: Celso Bastos, 1999.

. Teoria da ciência jurídica. São Paulo: Saraiva, 2001.

HESSE, Konrad. Escritos de Derecho Constitucional. Madri: Centro de Estúdios Constitucionales, 1983.

LOEWENSTEIN, Karl. Teoría de la Constituición. Trad. para espanhol de Alfredo Gallego Anabitarte. Barcelona: Ediciones Ariel, 1970.

LOPES, João Batista. Curso de Direito Processual Civil: parte geral. São Paulo: Atlas, 2005. v. 1

MARTINS, Ives Gandra da Silva. Transação e arbitragem no Direito Tributário. In: PUCCI, Adriana Noemi (Coord.). Aspectos atuais da arbitragem: coletânea de artigos dos árbitros do centro de conciliação e arbitragem da câmara de comércio argentino-brasileira de São Paulo. Rio de Janeiro: Forense, 2001. 
MARTINS, Ives Gandra; BASTOS, Celso Ribeiro. Comentários à Constituição do Brasil: promulgada em 5 de outubro de 1988. São Paulo: Saraiva, 1988-1989. MUNIZ, Tânia Lobo. Arbitragem no Brasil e a Lei n 9.307/96. Curitiba: Juruá, 2006.

NALINI, José Roberto. O juiz e o acesso à justiça. São Paulo: RT, 1994.

NERY JÚNIOR, Nelson. Princípios do processo civil na Constituição Federal. 8. ed. São Paulo: RT, 2004.

NOHMI, Antônio Marcos. Arbitragem internacional: mecanismos de solução de conflitos entre Estados. Belo Horizonte: Del Rey, FCH-FUMEC, 2005.

PUCCI, Adriana Noemi (Coord.). Aspectos Atuais da Arbitragem: coletânea de artigos dos árbitros do centro de conciliação e arbitragem da câmara de comércio argentino-brasileira de São Paulo. Rio de Janeiro: Forense, 2001.

RECHSTEINER, Beat Walter. Arbitragem privada internacional no Brasil depois da Lei 9.307, de 23.09.1996: teoria e prática. 2. ed. São Paulo: RT, 2001.

RIBEIRO, Paulo de Tarso. Direito e processo: razão burocrática e acesso à justiça. São Paulo: Mas Limonad, 2002.

SANT’ANA, Valéria Maria. Arbitragem: comentários à lei nª 9.307, de 23.09.96. São Paulo: Edipro, 1997.

SANTOS, Paulo de Tarso. Arbitragem e poder judiciário: mudança cultural. São Paulo: LTr, 2001.

SOUZA NETO, João Baptista de Mello e. Mediação em juízo: abordagem prática para obtenção de um acordo justo. São Paulo: Atlas, 2000.

THEODORO JÚNIOR, Humberto. Curso de Direito Processual Civil: teoria geral do direito processual civil e processo de conhecimento. 36. ed. Rio de Janeiro: Forense, 2001. v. 1.

TUCCI, Rogério Lauria; CRUZ E TUCCI, José Rogério. Constituição de 1988 e Processo. São Paulo: Saraiva, 1989. v. 1.

WAMBIER, Luiz Rodrigues (Coord.). Curso Avançado de Processo Civil: teoria geral do processo e processo de conhecimento. 9. ed. São Paulo: RT, 2007.

WATANABE, Kazuo. Acesso à justiça e sociedade moderna. In: GRINOVER, Ada Pellegrini; DINAMARCO, Cândido Rangel; WATANABE, Kazuo (Coord.). Participação e processo. São Paulo: Revista dos Tribunais, 1988. 
YOSHIDA, Márcio. A Arbitragem no Âmbito do Direito do Trabalho. In: GARCEZ, José Maria Rossani (Coord.). A arbitragem na era da globalização: coletânea de artigos de autores brasileiros e estrangeiros. Rio de Janeiro: Forense, 1997.

Artigo recebido em 10/08/09 e aceito em 08/09/09 